\title{
Antimicrobial Hypochlorous Wound Irrigation Solutions Demonstrate Lower Anti-biofilm Efficacy Against Bacterial Biofilm in a Complex in-vitro Human Plasma Biofilm Model (hpBIOM) Than Common Wound Antimicrobials
}

OPEN ACCESS

Edited by:

Sujogya Kumar Panda, KU Leuven, Belgium

Reviewed by: Idalina Machado, University of Porto, Portugal Tim Maisch

University of Regensburg, Germany Seok Hong,

Northwestern University, United States

*Correspondence: Julian-Dario Rembe julian-dario.rembe@uni-wh.de

tThese authors share first authorship

Specialty section: This article was submitted to Antimicrobials, Resistance and Chemotherapy,

a section of the journal Frontiers in Microbiology

Received: 21 May 2020 Accepted: 11 September 2020 Published: 09 October 2020

Citation:

Rembe JD, Huelsboemer L, Plattfaut I, Besser $M$ and Stuermer EK (2020) Antimicrobial Hypochlorous Wound Irrigation Solutions Demonstrate Lower Antibiofilm Efficacy Against Bacterial Biofilm in a Complex in-vitro Human Plasma Biofilm Model (hpBIOM) Than Common Wound Antimicrobials. Front. Microbiol. 11:564513. doi: 10.3389/fmicb.2020.564513

\author{
Julian-Dario Rembe ${ }^{1 * t}$, Lioba Huelsboemer ${ }^{2 \dagger}$, Isabell Plattfaut ${ }^{2}$, Manuela Besser ${ }^{2}$ and \\ Ewa K. Stuermer ${ }^{3}$
}

\begin{abstract}
'Department of Vascular and Endovascular Surgery, University Hospital Düsseldorf, Heinrich-Heine-University of Düsseldorf, Düsseldorf, Germany, ${ }^{2}$ Chair for Translational Wound Research, Centre for Biomedical Education and Research, Witten/Herdecke University, Witten, Germany, ${ }^{3}$ Department of Vascular Medicine, University Heart and Vascular Center Hamburg, Translational Wound Research, University Medical Centre Hamburg-Eppendorf, Hamburg, Germany
\end{abstract}

Biofilms pose a relevant factor for wound healing impairment in chronic wounds. With $78 \%$ of all chronic wounds being affected by biofilms, research in this area is of high priority, especially since data for evidence-based selection of appropriate antimicrobials and antiseptics is scarce. Therefore, the objective of this study was to evaluate the anti-biofilm efficacy of commercially available hypochlorous wound irrigation solutions compared to established antimicrobials. Using an innovative complex in-vitro human plasma biofilm model (hpBIOM), quantitative reduction of Pseudomonas aeruginosa, Staphylococcus aureus, and Methicillin-resistant $S$. aureus (MRSA) biofilms by three hypochlorous irrigation solutions [two $<0.08 \%$ and one $0.2 \%$ sodium hypochlorite $(\mathrm{NaClO})$ ] was compared to a $0.04 \%$ polyhexanide (PHMB) irrigation solution and $0.1 \%$ octenidine-dihydrochloride/phenoxyethanol (OCT/PE). Efficacy was compared to a non-challenged planktonic approach, as well as with increased substance volume over a prolonged exposure (up to 72 h). Qualitative visualization of biofilms was performed by scanning electron microscopy (SEM). Both reference agents (OCT/PE and PHMB) induced significant biofilm reductions within $72 \mathrm{~h}$, whereby high volume OCT/PE even managed complete eradication of $P$. aeruginosa and MRSA biofilms after $72 \mathrm{~h}$. The tested hypochlorous wound irrigation solutions achieved no relevant penetration and eradication of biofilms despite increased volume and exposure. Only $0.2 \% \mathrm{NaClO}$ managed a low reduction under prolonged exposure. The results demonstrate that low-dosed hypochlorous wound irrigation solutions are significantly less effective than PHMB-based irrigation solution and OCT/PE, thus unsuitable for biofilm eradication on their own. The used complex hpBIOM thereby mimics the highly challenging clinical wound microenvironment, providing a more profound base for future clinical translation.

Keywords: wound infection, biofilm, antimicrobial, antiseptic, hypochlorous acid, human plasma biofilm model, wound irrigation, chronic wound 


\section{INTRODUCTION}

In wound management, controlling microbial bioburden is a key factor of prophylactic and therapeutic regimes. While wound contamination and colonization can mostly be handled with vigilance and mechanical cleansing, local infection with the potential threat of systemic spread requires antimicrobial intervention (IWII, 2016). Possible interventions range from preserved antimicrobialscontaining wound irrigation solutions to antiseptics, debridement and systemic antibiotics in case of systemic spread. Biofilm formation thereby represents a specifically difficult to diagnose and manage complication in wound therapy. According to recent evaluations, over $78 \%$ of all chronic wounds are challenged by biofilm formation (Malone et al., 2017). Biofilms are structured communities of microorganisms attached to a surface (e.g., wound bed) encased within an extracellular matrix (ECM) referred to as the extracellular polymeric substance (EPS; Percival et al., 2015). Microorganisms embedded in the EPS demonstrate a significant tolerance and resilience to antimicrobial substances, biocides, and the host immunity due to a variety of factors such as polymicrobial heterogeneity, genetic diversity, and resistance transfer, dormant metabolism and the EPS itself functioning as a high-protein mechanical and diffusion barrier for antimicrobials (Hall-Stoodley and Stoodley, 2009; Hoiby et al., 2010; Percival et al., 2015; Salisbury et al., 2018). As a result, wound antimicrobials and antiseptics need to be thoroughly investigated regarding their anti-biofilm efficacy (Schultz et al., 2017).

Several in-vitro models have been applied for this purpose, growing wound biofilms on plastic or metal surfaces, in many cases without additional organic and/or human material (Brackman and Coenye, 2016; Schultz et al., 2017; Shukla et al., 2020). Such approaches are feasible for evaluating biocides and disinfectants for (surface) decontamination, but in case of wound antimicrobials, the more complex composition of the wound microenvironment (cytokines, proteases, fibrin, cells, etc.) with high-protein, organic challenge as well as the human immune system need to be considered. Therefore, our research group developed an innovative human plasma biofilm model (hpBIOM) for quantifiable testing of anti-biofilm activity of antimicrobial and antiseptic agents in a challenging wound biofilm environment, aiming to resemble the in-vivo situation (Besser et al., 2019, 2020).

Due to the recent renaissance of hypochlorous acid based antimicrobial wound irrigation solutions (Severing et al., 2019) with contrasting evidence regarding anti-biofilm efficacy, this study focused on the evaluation of these agents compared to established antimicrobial and antiseptic agents. Prolonged exposure times, increased substance volumes, and varying agents (with differing substance concentrations) were investigated using the hpBIOM and compared to a planktonic test setup to provide a comprehensive analysis.

\section{MATERIALS AND METHODS}

\section{Microbial Strains}

Staphylococcus aureus (DSM-799) and Pseudomonas aeruginosa (DSM-939; both German Collection of Microorganisms and Cell Cultures (DSMZ), Braunschweig, Germany) as well as a clinical MRSA strain (provided by the Institute for Medical Laboratory Diagnostics, Helios University Hospital Wuppertal, Germany) were selected. All strains were previously tested for biofilm formation on plastic surfaces (data not shown). All strains were cultivated on casein/soy peptone agar plates (CSA) according to standard protocols and the second subculture was used for experiments.

\section{Antimicrobials and Antiseptics}

Five antimicrobial solutions in total (Table 1) were evaluated. Three chlorine-based and -releasing agents, used as antimicrobial wound irrigation solutions: ActiMaris ${ }^{\circledR}$ forte $[0.2 \%$ sodium hypochlorite $(\mathrm{NaClO}) / 3 \%$ sal maris; AMF], Lavanox ${ }^{\circledR}(<0.08 \%$ $\mathrm{NaClO} ; \mathrm{LVX})$, and $\mathrm{Kerrasol}^{\circledR}(<0.08 \% \mathrm{NaClO} ; \mathrm{KSL})$.

As reference substances, a polyhexanide (PHMB)-based antimicrobial irrigation solution (Lavasorb ${ }^{\circledR} ; 0.04 \%$ PHMB) and the antiseptic Octenidine-dihydrochloride/phenoxyethanol (Octenisept ${ }^{\circledR} ; 0.1 \%$ OCT/PE) were used. All products were handled in a sterile manner and according to manufacturer instructions.

\section{Neutralizing Agent and Dissolving Solution}

To stop antimicrobial activity after specific designated exposure times, a neutralizing solution was used comprising of $40 \mathrm{~g}$ Tween 80, $30 \mathrm{~g}$ saponin, $4 \mathrm{~g}$ lecithin, $3 \mathrm{~g}$ sodium thiosulfate (all Carl Roth GmbH \& Co. KG, Karslruhe, Germany) and $10 \mathrm{~g}$ sodium dodecyl sulfate (SDS; Caesar \& Loretz $\mathrm{GmbH}$, Hilden, Germany), and $500 \mathrm{ml}$ double distilled $\mathrm{H}_{2} \mathrm{O}\left(\mathrm{ddH}_{2} \mathrm{O}\right)$. The neutralizing solution composition was based on specifications from the standards (DIN EN 13727; DIN, 2013). Concentration, volume, and efficacy of the neutralizing solution have been preliminarily validated internally and demonstrated a sufficient

TABLE 1 | Overview of the tested antiseptics and antimicrobial wound irrigation solutions, product specifications, manufacturer, and composition as specified by the manufacturer.

\begin{tabular}{|c|c|c|c|c|c|}
\hline \multicolumn{2}{|c|}{ Test solution } & \multirow{2}{*}{$\begin{array}{l}\text { Product } \\
\text { Octenisept }^{\circledR}\end{array}$} & \multirow{2}{*}{$\begin{array}{l}\text { Manufacturer } \\
\text { Schülke \& Mayr GmbH }\end{array}$} & \multirow{2}{*}{\begin{tabular}{l} 
Composition \\
\multicolumn{1}{c}{ Com g octenidin-dihydrochlorid, $2.0 \mathrm{~g}$ 2-phenoxyethanol } \\
(per $100 \mathrm{ml})$
\end{tabular}} & \multirow{2}{*}{$\begin{array}{l}\text { Category } \\
\text { Antiseptic }\end{array}$} \\
\hline $\mathrm{OCT} / \mathrm{PE}$ & & & & & \\
\hline PHMB & & Lavasorb ${ }^{\circledR}$ & Fresenius Kabi AG & $\begin{array}{l}0.4 \mathrm{~g} \text { polyhexanide, } 0.02 \mathrm{~g} \text { macrogolum 4,000 (per } \\
1,000 \mathrm{ml} \text { ) }\end{array}$ & Antimicrobial irrigation solution \\
\hline \multirow{3}{*}{$\mathrm{NaClO}$} & AMF & ActiMaris ${ }^{\circledR}$ forte & ActiMaris AG & $0.2 \% \mathrm{NaClO}, 3 \%$ sea-salt, $\mathrm{H}_{2} \mathrm{O}$ & Antimicrobial irrigation solution \\
\hline & LVX & Lavanox $^{\circledR}$ & Serag Wiessner GmbH \& Co KG & $\mathrm{H}_{2} \mathrm{O},<0.08 \% \mathrm{NaClO}$ & Antimicrobial irrigation solution \\
\hline & KSL & KerraSol $^{\mathrm{TM}}$ & Crawford Healthcare GmbH & $\mathrm{H}_{2} \mathrm{O},<0.08 \% \mathrm{NaClO}$ & Antimicrobial irrigation solution \\
\hline
\end{tabular}


neutralizing efficacy for all tested antiseptics and antimicrobials, non-toxicity toward microbial strains used in a planktonic, as well as a biofilm setup and showed no interference with the integrity of the biofilm model.

For dissolving the model after successful conduction of experiments to recover and quantify surviving microorganisms, a $10 \%(\mathrm{w} / \mathrm{v})$ bromelain solution was used, as bromelain exhibits a fibrinolytic activity and has been previously used for debridement and biofilm dispersal purposes (Maurer, 2001; Pavan et al., 2012; Besser et al., 2019, 2020). Therefore, 10 tablets of Bromelain-POS ${ }^{\circledR}$ (500 F.I.P. units per tablet; URSAPHARM Arzneimittel GmbH, Saarbrücken, Germany) were dissolved in $100 \mathrm{ml}$ phosphate buffered saline (PBS) and the solution stored at $4^{\circ} \mathrm{C}$ until further use. Bromelain was later added to the model in a $1: 1(\mathrm{v} / \mathrm{v})$ ratio to the model volume (1.5 ml per model). Before usage, bromelain was warmed to $37^{\circ} \mathrm{C}$ for improved enzyme performance. The bromelain solution has been preliminarily tested and validated and showed no antimicrobial effect of its own.

\section{Human Plasma Biofilm Model Preparation}

The development and use of the hpBIOM has been described in detail elsewhere (Besser et al., 2019, 2020) and was adapted to fit the specific agents and purpose pursued here. In brief, human plasma (citrate buffered) and buffy coat from anonymous donors were obtained from the DRK-Blutspendedienst West (Hagen, Germany). To remove as many residual erythrocytes as possible, the buffy coat was centrifuged at 3,000 rpm at room temperature (RT) for $30 \mathrm{~min}$. Subsequently, plasma and buffy coat were merged, gently mixed in a sterile glass bottle, and continuously agitated at $22^{\circ} \mathrm{C}$. A microbial test suspension was prepared by colony picking and adjusted to a $0.5 \mathrm{McF}$ arland standard $\left(\sim 1.5 \times 10^{8} \mathrm{cfu} / \mathrm{ml}\right)$ using a spectrophotometer $\left(\right.$ EON $^{\text {TM}}$; BioTek Germany, Bad Friedrichshall, Germany). Finally, a "master mix" was prepared by adding the appropriate amount of microbial test solution to the plasma and buffy coat mixture, resulting in a final bacterial concentration of $\sim 1.5 \times 10^{6} \mathrm{cfu}$ per individual hpBIOM. Next, $18.26 \mu$ calcium chloride $\left(\mathrm{CaCl}_{2}\right.$; $500 \mathrm{mM}$ ) per $\mathrm{ml}$ plasma was added to the master mix, to induce fibrin polymerization, gently mixed, and immediately transferred into 12 -well plates $(1.5 \mathrm{ml}$ per model/well containing plasma, buffy coat, and pathogenic bacteria). The plates were incubated for $12 \mathrm{~h}$ on a rotation shaker at $50 \mathrm{rpm}$ and $37.0^{\circ} \mathrm{C}$ for the plasma solution to polymerize with pathogens rearranging and forming an ECM, finally yielding a stable biofilm disc/ clot with integrated bacteria ( concentration of $\left.1.5 \times 10^{7} \mathrm{cfu} / \mathrm{ml}\right)$, EPS as well as human plasma and immune cells.

\section{Antimicrobial Treatment of the hpBIOM and Quantification of Bacterial Survival}

After hpBIOM preparation, each clot was treated with $300 \mu \mathrm{l}$ of antiseptic/antimicrobial test substance for $0.5,2,6$, and $24 \mathrm{~h}$. To additionally investigate the effect of prolonged exposure (in terms of remanence effect without reapplication) and/or increased substance volume $(1 \mathrm{ml})$, experiments were additionally extended to 48 and $72 \mathrm{~h}$ with $300 \mu \mathrm{l}$ or $1 \mathrm{ml}$ of active substance against the clinically isolated MRSA strain and P. aeruginosa. After the specified treatment periods, antimicrobial activity was neutralized by adding $1.2 \mathrm{ml}$ of the specified neutralizing solution to each well, detaching the model from the well walls with a pipette tip (in order to fully distribute the neutralizing solution around the model) and placing the plates on a rotation shaker at RT for $5 \mathrm{~min} \pm 10 \mathrm{~s}$. Subsequently, each hpBIOM was carefully transferred into a $15 \mathrm{ml}$ falcon tube with $1 \mathrm{ml}$ bromelain solution for dissolving the model. An additional $0.5 \mathrm{ml}$ of bromelain solution was used to wash out the well to detach remaining microorganisms and added to the falcon tube.

In case of the $1 \mathrm{ml}$ test setup, models were already detached and transferred into $15 \mathrm{ml}$ falcon tubes for neutralization, due to the higher necessary amount of neutralizing solution $(4 \mathrm{ml}$ to keep a 1:8 ratio) and bromelain subsequently added to the tube after neutralization. After $2-3 \mathrm{~h}$, the hpBIOM was completely dissolved. For quantification, the resulting solution was thoroughly vortexed, serially tenfold diluted, $50 \mu \mathrm{l}$ of each dilution spread on agar plates and incubated overnight at $37^{\circ} \mathrm{C}$ under aerobic conditions. Remaining microbial counts after treatment were quantified by determining colony counts (in $\mathrm{cfu} / \mathrm{ml}$ ) using a Colony Counter Pen (eCount ${ }^{\mathrm{TM}}$, VWR Leicestershire, United Kingdom) and reduction rates calculated compared to an untreated control, as well as initial bacterial counts.

\section{Quantitative Suspension Method}

To compare the anti-biofilm efficacy of the tested antiseptics and antimicrobials to the efficacy on planktonic bacteria, all tested substances were additionally evaluated using a quantitative suspension method (QSM). The QSM is based on DIN EN 13727 (DIN, 2013) and has been modified for direct comparison to the hpBIOM. Thereby, a bacterial test suspension was prepared by colony picking, adjusted to $1.5 \times 10^{7} \mathrm{cfu} / \mathrm{ml}$ initial concentration (as for hpBIOM) and $1.5 \mathrm{ml}$ of the prepared bacterial test suspension was treated with $300 \mu \mathrm{l}$ of the respective antiseptic or antimicrobial for $0.5,2,6$, or $24 \mathrm{~h}$. To neutralize antimicrobial activity, $1.2 \mathrm{ml}$ neutralizing solution was added and the samples subsequently incubated for $5 \mathrm{~min} \pm 10 \mathrm{~s}$ on a rotation shaker at RT. Reduction rates (in $\mathrm{cfu} / \mathrm{ml}$ ) were quantified in the same manner as described for hpBIOM.

\section{Visualization of Biofilm Using Scanning Electron Microscopy}

To visualize the morphology and structure of the bacterial biofilm with and without antiseptic/antimicrobial treatment, scanning electron microscopy (SEM) was performed for selected experimental setups (see Table 2). After neutralization of the antiseptic/ antimicrobial agents, the models were fixed with a glutaraldehyde/ PVP-solution containing $2.5 \%$ glutaraldehyde, $2 \%$ polyvinylpyrrolidone (PVP), and $0.5 \%$ sodium nitrite $\left(\mathrm{NaNO}_{2}\right)$ in $0.1 \mathrm{M}$ cacodylate buffer for $1 \mathrm{~h}$ at $4^{\circ} \mathrm{C}$. Samples were washed in $0.1 \mathrm{M}$ cacodylate buffer and stored at $4^{\circ} \mathrm{C}$ until preparation of freeze fracture fragments with liquid nitrogen. For glycocalyx staining, the samples were subsequently incubated in a solution containing $2 \%$ arginine-hydrochloride (HCL), glycine, sucrose, and 
TABLE 2 | Specification and overview of the experimental setups used for visualization of biofilm formation in the human plasma biofilm model (hpBIOM) using scanning electron microscopy (SEM).

\begin{tabular}{lllcc}
\hline Image & $\begin{array}{l}\text { Setup/ } \\
\text { substance }\end{array}$ & Pathogen & $\begin{array}{c}\text { Maturation } \\
\text { time* }\end{array}$ & $\begin{array}{c}\text { Treatment } \\
\text { period }\end{array}$ \\
\hline 4 (a) & CTRL & P. aeruginosa & $12 \mathrm{~h}$ & - \\
4 (b) & $\mathrm{CTRL}$ & P. aeruginosa & $18 \mathrm{~h}$ & - \\
4 (c) & $\mathrm{CTRL}$ & P. aeruginosa & $36 \mathrm{~h}$ & - \\
5 (a) & $\mathrm{CTRL}$ & P. aeruginosa & $12 \mathrm{~h}$ & $0 \mathrm{~h}$ \\
5 (b) & $\mathrm{OCT} / \mathrm{PE}$ & P. aeruginosa & $12 \mathrm{~h}$ & $6 \mathrm{~h}$ \\
5 (c) & $\mathrm{OCT} / \mathrm{PE}$ & P. aeruginosa & $12 \mathrm{~h}$ & $24 \mathrm{~h}$ \\
5 (d) & $\mathrm{NaOCl}$ & P. aeruginosa & $12 \mathrm{~h}$ & $24 \mathrm{~h}$ \\
& $(<0.08 \%)$ & & & \\
\hline
\end{tabular}

Figures $4 \mathbf{A}-\mathbf{C}$ demonstrate a representative biofilm development over time. Figures 5A-D show the biofilm surface structure under treatment with antiseptics (OCT/PE) or antimicrobial wound irrigation solution ( $<0.08 \% \mathrm{NaOCl}$ ) over time compared to the initial structure. "Before application of test substance, if any (not in case of CTRL).

sodium glutamate for $18 \mathrm{~h}$ at RT. The samples were rinsed with $\mathrm{ddH}_{2} \mathrm{O}$ and $0.1 \mathrm{M}$ cacodylate buffer followed by immersion in a mixture of $2 \%$ tannic acid and guanidine-HCL for $5.5 \mathrm{~h}$ at RT. After another rinsing step with $\mathrm{ddH}_{2} \mathrm{O}$ and $0.1 \mathrm{M}$ cacodylate buffer samples were incubated over night at $4^{\circ} \mathrm{C}$. For staining, the samples were placed in a $1 \%$ osmium tetroxide $\left(\mathrm{OsO}_{4}\right)$ solution for $30 \mathrm{~min}$ at RT. After three rinsing steps with $0.1 \mathrm{M}$ cacodylate buffer, the samples were again stored over night at $4^{\circ} \mathrm{C}$. Finally, samples were dehydrated using isopropyl alcohol and acetone and dried in liquid $\mathrm{CO}_{2}$ using a critical point dryer (BAL-TEC AG, Balzers, Liechtenstein). Via the sputter coater (BAL-TEC AG, Balzers, Liechtenstein), samples were sputtered with gold palladium and finally examined with a Zeiss Sigma SEM (Zeiss, Oberkochen, Germany) using $2 \mathrm{kV}$ acceleration voltage and an inlens detector.

\section{Statistical Analysis}

All experiments were performed in triplicates with three different anonymous donors. Microbial reduction rates (in $\Delta \log _{10} \mathrm{cfu} /$ $\mathrm{ml}$ ) were calculated for all tested antiseptic/antimicrobial solutions. High antimicrobial efficacy is defined as a reduction in initial microbial counts by at least $3 \log _{10}$ reduction steps, as defined for antiseptics tested under organic challenge by national and international standards (DIN, 2013). Data are expressed as means \pm standard error of the mean (sem) and were analyzed using the statistics program GraphPad PRISM (Version 8.2.1; GraphPad Software Inc., La Jolla, United States). Statistical analysis was performed using two-way ANOVA, followed by Holm-Sidak posthoc test for evaluation of multiple comparisons. A value of $p \leq 0.05$ was considered statistically significant $\left({ }^{*} p \leq 0.05 ;{ }^{* *} p \leq 0.01 ;{ }^{* * * *} p \leq 0.001\right.$; and $\left.{ }^{* * * * *} p \leq 0.0001\right)$.

\section{RESULTS}

\section{Antimicrobial Efficacy on Planktonic Bacteria (QSM) Within 24 H}

On bacteria in a planktonic state, the three tested antimicrobial hypochlorous wound irrigation solutions containing $\mathrm{NaClO} /$ hypochlorous acid $(\mathrm{HClO})$ demonstrated no bacterial reduction against any tested pathogen within $24 \mathrm{~h}$ (Figure 1).

Both reference substances, OCT/PE and PHMB-based irrigation solution, achieved a highly significant reduction of $P$. aeruginosa $\left(4.77 \pm 1.41\right.$ and $5.25 \pm 0.93 \log _{10}$ steps, respectively; $p<0.0001), S$. aureus $\left(6.18 \pm 0.00\right.$ and $4.82 \pm 1.36 \log _{10}$ steps; $p<0.0001$ ), and MRSA (both $6.18 \pm 0.00 \log _{10}$ steps; $p<0.0001$ ) within $30 \mathrm{~min}$ of exposure (Figures 2A-C). After $2 \mathrm{~h}$ of exposure, OCT/PE and $\mathrm{PHMB}$ both fully eradicated all three tested pathogens, except PHMB against $S$. aureus, needing $6 \mathrm{~h}$ for complete eradication (Figure 2C).

All reduction rates of the QSM are summarized in Supplementary Table 1 .

\section{Anti-biofilm Efficacy (hpBIOM) Within 24 H}

As in the QSM, the tested hypochlorous wound irrigation solutions showed no antimicrobial/anti-biofilm activity in the complex biofilm model (hpBIOM). No bacterial reduction could be observed against any tested pathogen within $24 \mathrm{~h}$ (Figure 1).

The tested reference substances showed a reduced effect within 24 h: against a methicillin-resistant (MRSA) as well as a methicillin-susceptible (MSSA) S. aureus biofilm, PHMB showed no statistically significant reduction within $24 \mathrm{~h}$ compared to an untreated control (Figures 2B,C; $p=0.90 / 0.93$ ), while OCT/PE managed a statistically significant low reduction of $0.83 \pm 0.23$ (Figure $2 \mathbf{B} ; p=0.014$ ) and $1.28 \pm 0.32 \log _{10}$ steps (Figure 2C; $p=0.0002$ ).

A higher efficacy could be observed against $P$. aeruginosa biofilms. Both antiseptics induced a statistically significant reduction within $24 \mathrm{~h}$ of treatment compared to the control, whereby OCT/PE achieved $2.68 \pm 0.46 \log _{10}$ steps $(p=0.0008)$ and PHMB $2.97 \pm 0.59 \log _{10}$ steps (Figure 2A; $p=0.0002$ ).

\section{Anti-biofilm Efficacy (hpBIOM) Under Prolonged Exposure (up to $72 \mathrm{H}$ ) and/or Increased Substance Volume (1 ml)}

Prolonged exposure times of up to $72 \mathrm{~h}$ for $0.3 \mathrm{ml} \mathrm{OCT} / \mathrm{PE}$ and $\mathrm{PHMB}$ increased bacterial reduction of all three pathogens with a continuous decrease in bacterial counts yielding highest reductions after $72 \mathrm{~h}$ of exposure compared to the untreated control (Figures 2A-C). For MRSA and MSSA, OCT/PE reached higher overall reduction rates than PHMB after $72 \mathrm{~h}$ (MRSA: $4.45 \pm 1.73$ vs. $0.96 \pm 0.79 \log _{10}$; MSSA $-2.19 \pm 0.29$ vs. $0.97 \pm 0.79 \log _{10}$; Figures $\left.2 B, C\right)$. Against $P$. aeruginosa biofilms, $\mathrm{PHMB}$ achieved higher reduction rates than OCT/PE after $72 \mathrm{~h}\left(4.23 \pm 1.95\right.$ vs. $3.54 \pm 1.34 \log _{10}$; Figure $\left.2 \mathrm{~A}\right)$. In case of antimicrobial hypochlorous irrigation solutions, a prolonged exposure with $0.3 \mathrm{ml}$ showed no improved effect (Figure 1).

When increasing the substance volume per treatment to $1.0 \mathrm{ml}$, both OCT/PE and PHMB demonstrated a significant increase of bacterial reduction within $24 \mathrm{~h}$ compared to $0.3 \mathrm{ml}$ (Figure 3). OCT/PE achieved a nearly complete eradication of MRSA and $P$. aeruginosa after $24 \mathrm{~h}$ and especially against MRSA biofilms, it showed a significantly higher reduction than PHMB (5.64 \pm 0.53 vs. $1.63 \pm 0.63 \log _{10} ; p<0.0001$; Figure 3B). For hypochlorous solutions, an increase in volume did not 


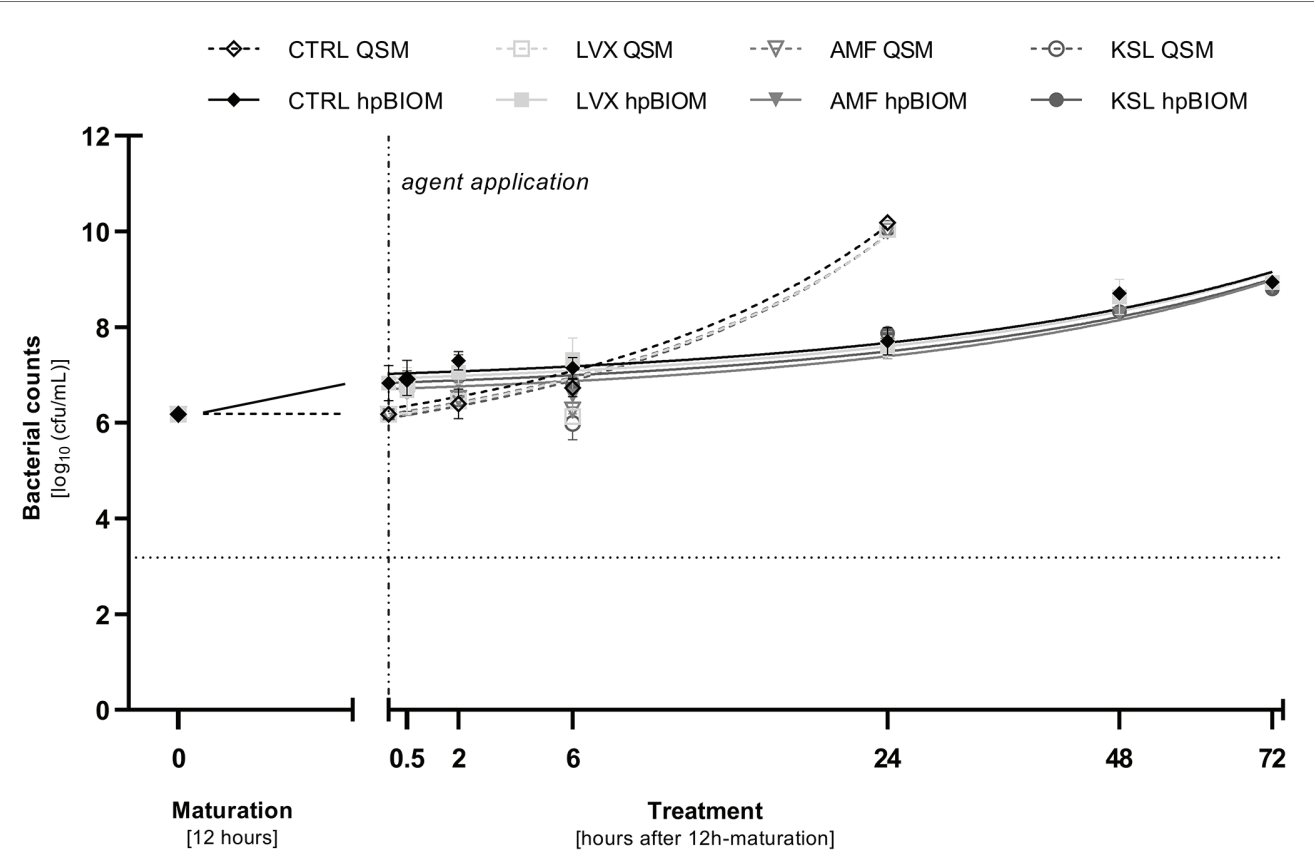

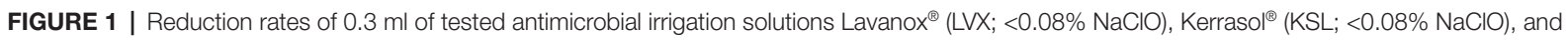
Actimaris ${ }^{\circledast}$ forte (AMF; $0.2 \% \mathrm{NaClO}, 3 \%$ sal maris) compared to an untreated control (CTRL) in planktonic (QSM) and biofilm (hpBIOM) form (here against Pseudomonas aeruginosa). Bacterial counts (in $\log _{10} \mathrm{cfu} / \mathrm{ml}$ ) are outlined over the course of $72 \mathrm{~h}$ of treatment after an initial biofilm maturation period of $12 \mathrm{~h}$. Dotted horizontal line indicates the cut-off for a high antimicrobial efficacy $\left(\geq 3 \log _{10}\right.$ reduction steps). Dashed vertical line indicates onset of treatment with the different antimicrobial agents after $12 \mathrm{~h}$ of biofilm maturation. Values are expressed as means \pm standard error of the mean (sem) and time-kill-curves of bacteria in planktonic state (QSM) are only depicted for $24 \mathrm{~h}$. All experiments were performed in triplicates.

result in an increase in antimicrobial efficacy within $24 \mathrm{~h}$ (Supplementary Table 2).

The highest anti-biofilm efficacy was observed under the combination of prolonged exposure and increased substance volume of $1 \mathrm{ml}$ (Figures 3A,B). OCT/PE managed to completely eradicate both MRSA and P. aeruginosa biofilms after $72 \mathrm{~h}$. In case of $P$. aeruginosa biofilms, $\mathrm{PHMB}$ achieved full eradication before OCT/PE, after only $48 \mathrm{~h}$ (Figure 3A), while against MRSA it proved significantly less effective $\left(2.73 \log _{10}\right.$ reduction steps less than OCT/PE after $72 \mathrm{~h} ; p=0.0004)$, not achieving complete eradication and even demonstrating a certain regrowth between 48 and $72 \mathrm{~h}$ (Figure 3B).

In terms of the antimicrobial hypochlorous solutions, the highest concentrated product (AMF; 0.2\% sodium hypochlorite) demonstrated a low bacterial reduction against MRSA biofilm of $1.35 \pm 0.58 \log _{10}$ steps $(p=0.0016)$ after 48 h. However, regrowth between 48 and $72 \mathrm{~h}$ could be observed (Figure 3B) as well.

\section{Scanning Electron Microscopy of the hpBIOM}

The monitoring and visualization of the hpBIOM using SEM (representative imaging provided from $P$. aeruginosa biofilms; Table 2) showed a good maturation and development of the biofilm with initial microcolony formation and subsequent development of EPS/glycocalyx, encapsulating bacteria (Figure 4) within $18 \mathrm{~h}$. After $36 \mathrm{~h}$ of maturation, a densely formed surface of interconnected, polymerized fibrins with encapsulated bacteria and densely distributed EPS can be observed.

Under treatment with hypochlorous solutions and antiseptics compared to no treatment, a loss in surface density of the biofilm model can be observed with increasing treatment time of the antiseptic OCT/PE (Figure 5). After $6 \mathrm{~h}$ of treatment, the biofilm surface shows an increased number of holes and less integrity compared to the initial untreated surface structure (Figure 5B). After $24 \mathrm{~h}$ of treatment, the surface is deranged and "broken-open" into a loosened structure with fine filaments, readily penetrable by $\mathrm{OCT} / \mathrm{PE}$ (Figure 5C). After $24 \mathrm{~h}$ of treatment with $<0.08 \% \mathrm{NaClO}$, the surface structure remained densely connected without visual loosening of surface structure or holes (Figure 5D). Additionally, newly build-up superficial EPS structures appeared, covering some area of the biofilm surface structure.

\section{DISCUSSION}

Biofilms pose a great challenge in chronic wound care and are a major factor for wound chronicity and impaired healing (James et al., 2008; Percival and Suleman, 2015; IWII, 2016; Percival, 2017; Schultz et al., 2017). Adequately addressing this challenge by improving knowledge and developing precise, comprehensive and new therapeutic strategies, including accurate agent efficacy profiles, is an important research goal in modern 
A

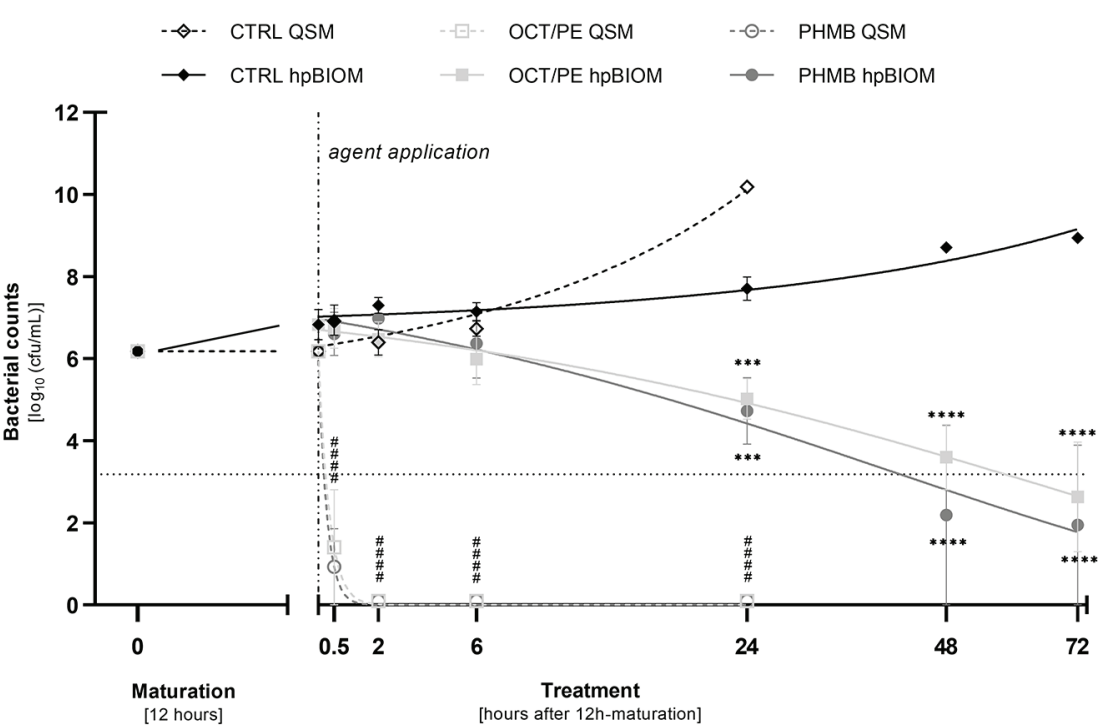

B

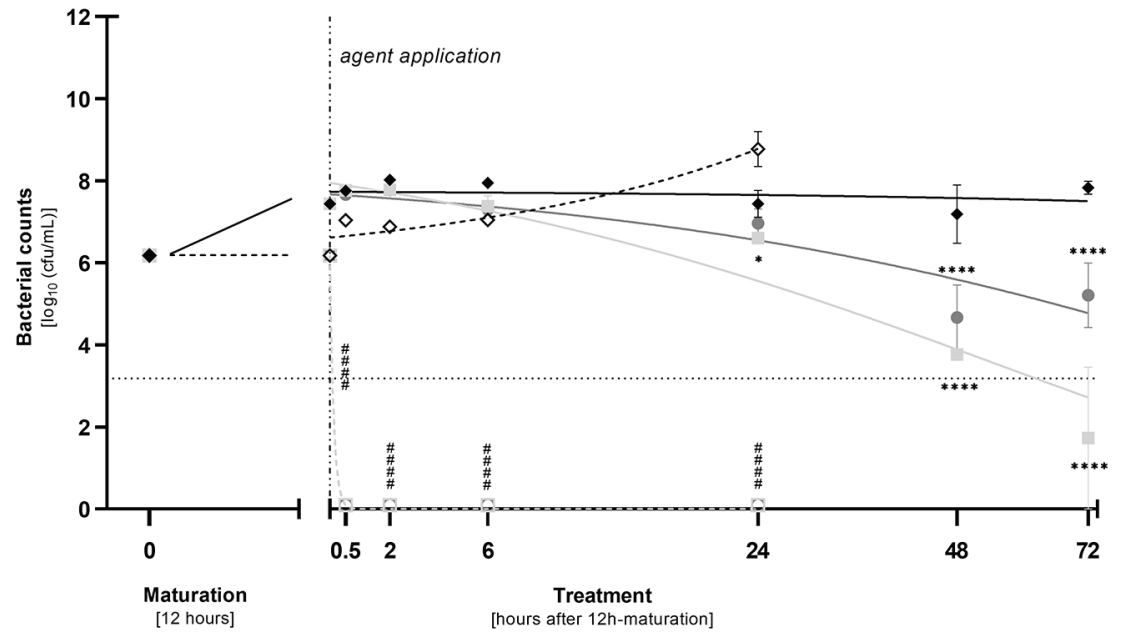

C

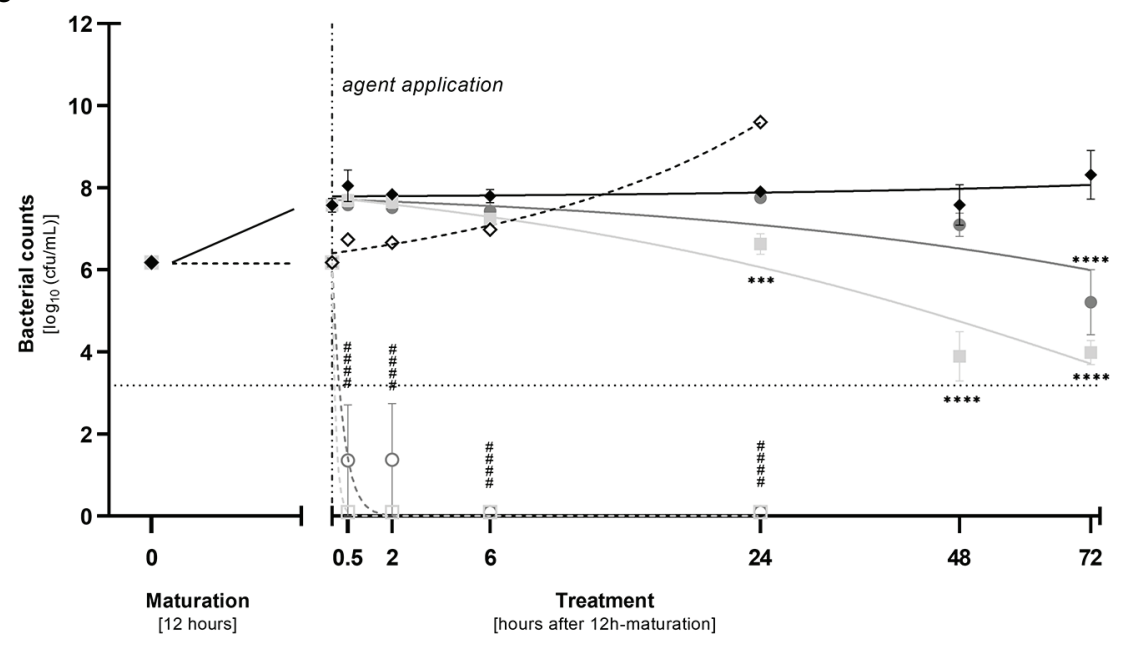

FIGURE 2 | (Continued) 
FIGURE 2 | Reduction of P. aeruginosa (A), MRSA (B), and S. aureus (C) in planktonic (QSM) vs. biofilm (hpBIOM) form by $0.3 \mathrm{ml}$ of tested antiseptics octenidine-dihydrochloride/phenoxyethanol (OCT/PE) and polyhexanide (PHMB) compared to an untreated control (CTRL). Remaining bacterial counts (in $\left.\log _{10} \mathrm{cfu} / \mathrm{ml}\right)$ are outlined over the course of $72 \mathrm{~h}$ of treatment after an initial biofilm maturation period of $12 \mathrm{~h}$. Dotted horizontal line indicates the cut-off for a high antimicrobial efficacy ( $\geq 3 \log _{10}$ reduction steps). Dashed vertical line indicates onset of treatment with the different antimicrobial agents after $12 \mathrm{~h}$ of biofilm maturation. Values are expressed as means \pm sem. Significant reductions compared to the untreated control are expressed as ${ }^{*} p \leq 0.05,{ }^{* *} p \leq 0.01$, ${ }^{* * * *} p \leq 0.001$, or ${ }^{* * * * *} p \leq 0.0001$ (\# in case of QSM). All experiments were performed in triplicates [Time-kill-curves of bacteria in planktonic state (QSM) are only depicted for $24 \mathrm{~h}$.

A

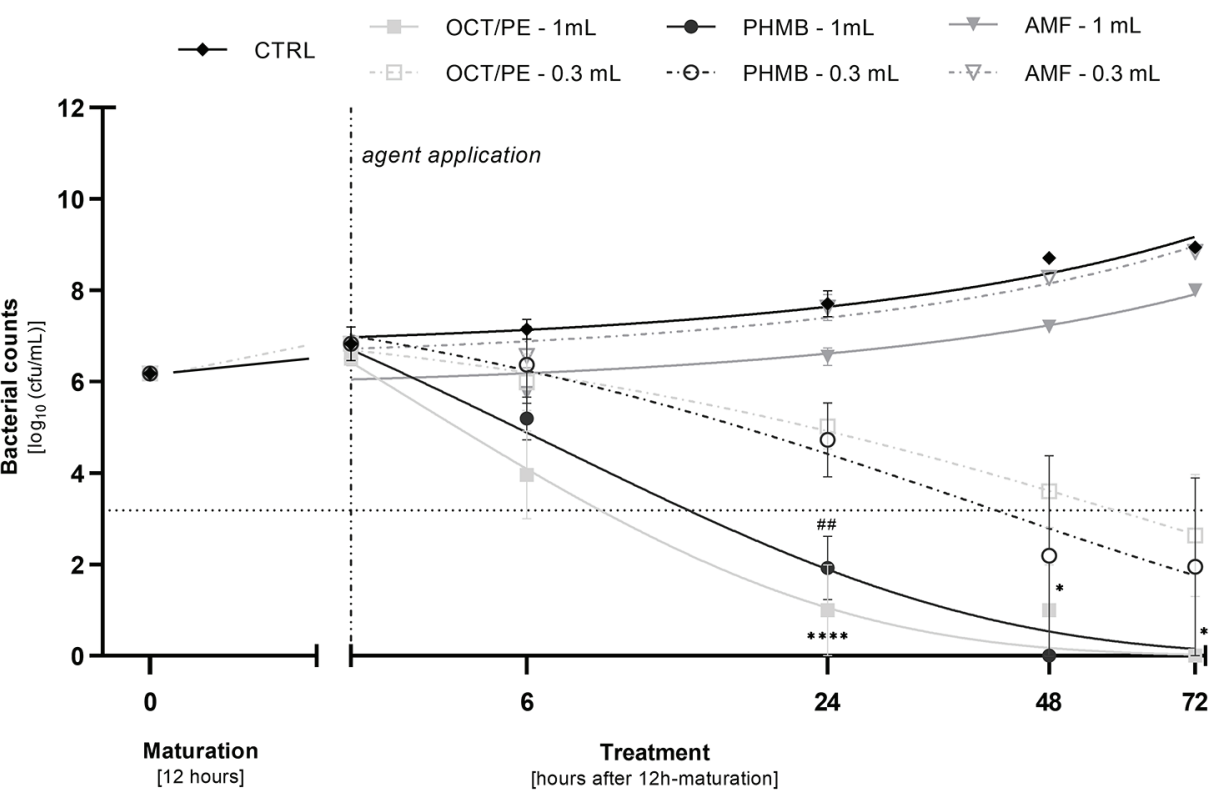

B

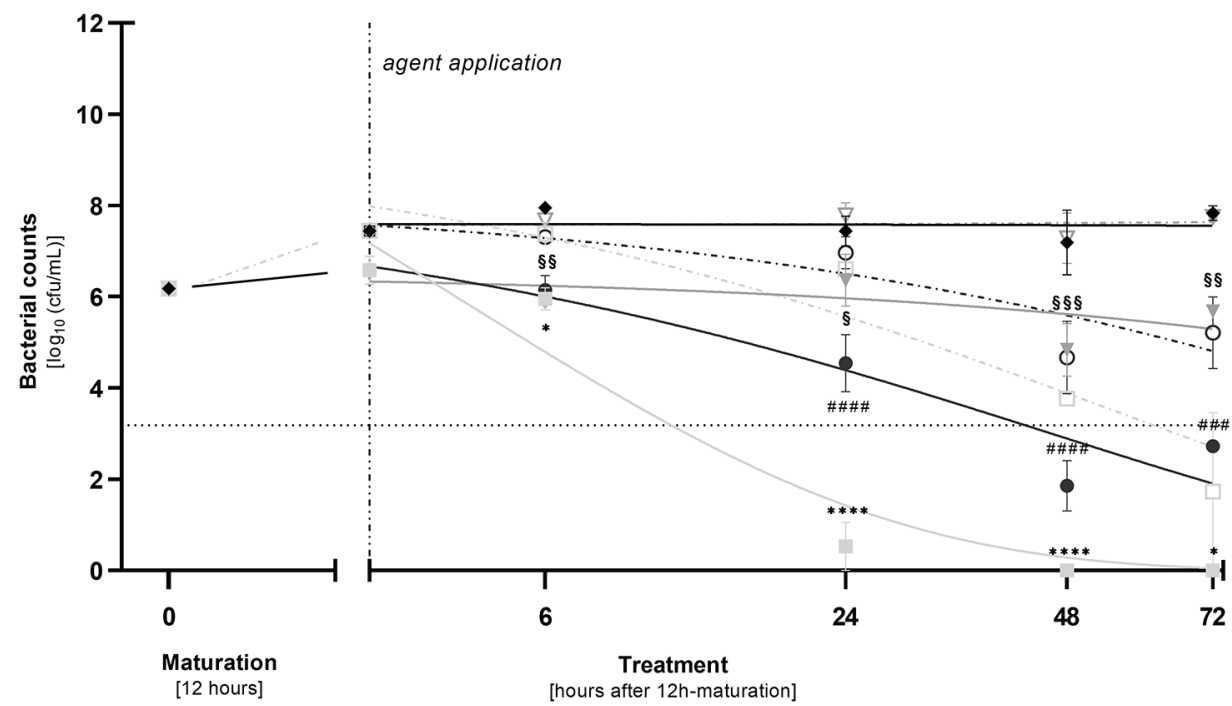

FIGURE 3 | Comparison of the reduction of $P$. aeruginosa (A) and MRSA (B) in the biofilm model (hpBIOM) between 0.3 and 1.0 ml of tested antimicrobial substances in a prolonged exposure of up to $72 \mathrm{~h}$. Graphs depict bacterial counts (in $\log _{10} \mathrm{cfu} / \mathrm{ml}$ ) after treatment with octenidine-dihydrochloride/phenoxyethanol (OCT/PE), polyhexanide (PHMB), or $0.2 \%$ sodium hypochlorite (AMF) compared to an untreated control (CTRL). Values are expressed as means \pm sem and a significant increase in reduction under $1.0 \mathrm{ml}$ substance volume is expressed as ${ }^{*} p \leq 0.05,{ }^{* * *} p \leq 0.01,{ }^{* * *} p \leq 0.001$, or ${ }^{* * * * *} p \leq 0.0001{ }^{*}$ for PHMB; \# for OCT/PE, and $\S$ for AMF). Dotted horizontal line indicates the cut-off for a high antimicrobial efficacy ( $\geq 3 \log _{10}$ reduction steps). Dashed vertical line indicates onset of treatment with the different antimicrobial agents after $12 \mathrm{~h}$ of biofilm maturation. All experiments were performed in triplicates. 
wound management (Schultz et al., 2017; Schwarzer et al., 2019; Stoffel et al., 2020).

Due to the extensive resilience of microorganisms residing within polymicrobial communities protected by EPS, rigorous and highly efficient anti-biofilm regimens are necessary. A form of repetitive, effective debridement represents the fundamental base of current anti-biofilm strategies (Wolcott et al., 2010; IWII, 2016; Schultz et al., 2017). Debridement alone, however, is insufficient for complete biofilm eradication (Schwartz et al., 2014; Schultz et al., 2017), as is the lone application of (even highly efficient) antimicrobial and antiseptic agents, making a combination of both approaches the current gold standard (Hoiby et al., 2015; Koo et al., 2017; Schultz et al., 2017). However, reported data on efficacy of available antimicrobial and antiseptic agents varies greatly depending on various factors and to date no agent can be clearly favored as being best suited for the treatment of chronic wound biofilms (Schultz et al., 2017; Schwarzer et al., 2019). Foremost, heterogeneity in study design/experimental setup and lacking transferability from adequate in-vitro to in-vivo studies and the clinical reality have been identified as a main limitation in current research (Schwarzer et al., 2019; Stoffel et al., 2020).

Another major concern is the sometimes liberal extrapolation of results in basic "non-challenging" test scenarios (e.g., antimicrobial efficacy in planktonic assays or biofilms grown on plastic surfaces without introduction of organic load) to clinical "real-world" situations. The significant differences in efficacy between a standard planktonic (DIN EN 13727; DIN, 2013) and in-vitro biofilm assay as well as between different forms of biofilm assays have been demonstrated before (Brackman and Coenye, 2016; Johani et al., 2018; Shukla et al., 2020) and could be reproduced in this study (Figures $\mathbf{2 A - C}$ ) when comparing reduction rates of QSM to hpBIOM. Where bacteria in a planktonic state are easily eradicated by the antiseptic OCT/PE and the PHMB-based antimicrobial irrigation solution within $30 \mathrm{~min}$, reduction rates are significantly reduced in the more complex hpBIOM (Figures 2A-C) which introduces organic challenge faced by antimicrobial agents in human biofilmburdened chronic wounds (higher protein load, hard-topenetrate EPS structure, immune cells, dormant bacteria, etc.). These results emphasize the dependency of an agent's performance based on the environment it acts in and are calling for more comprehensive testing of agents before recommendations can be declared.

Most static and liquid-flow-based in-vitro models are limited to factors such as growth on plastic surfaces and lack adequate organic conditions reflecting a wound environment, let alone the heterogenous, individual conditions in human chronic wound biofilms (Brackman and Coenye, 2016). The development of the hpBIOM (Figures 4A-C; Besser et al., 2019, 2020) aimed to narrow the gap between in-vitro and in-vivo biofilm research and provides a translational approach. The use of a complex biofilm model based on human material, including plasma and immune cells, addresses the interactions of microbial biofilms with the human wound micro-environment (James et al., 2008; Percival et al., 2015), as well as the relevant loss in efficacy
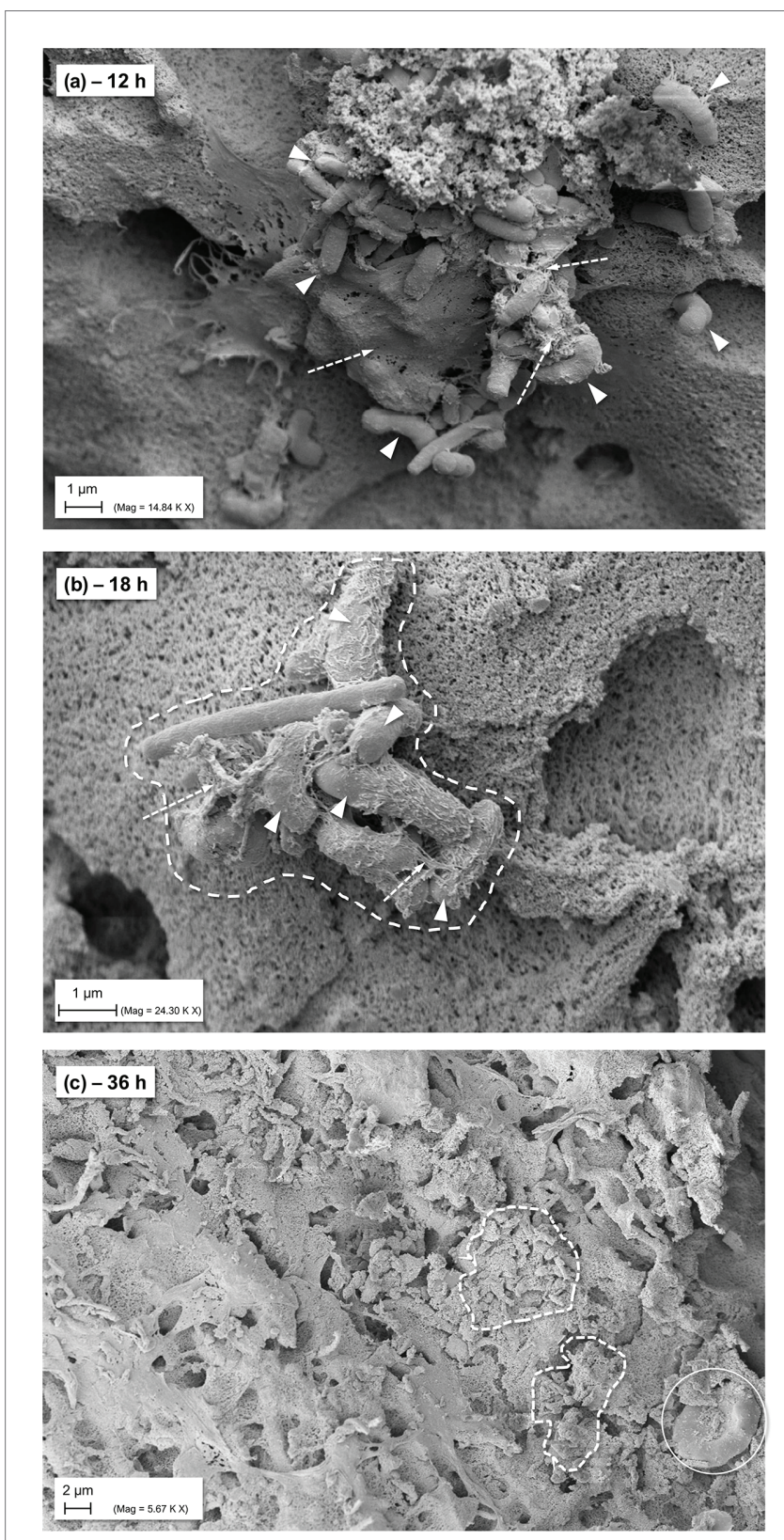

FIGURE 4 | SEM images of general biofilm maturation and development in the hpBIOM (here $P$. aeruginosa) without treatment (CTRL). (A) Formed microcolony in a $12 \mathrm{~h}$ maturated biofilm with bacterial attachment and initially formed extracellular polymeric substance (EPS)/glycocalyx (arrows with dashed lines); arrowheads indicate bacteria. (B) Eighteen hours matured biofilm: dashed framing circles bacterial microcolony with single bacteria (arrowheads) connected by EPS/glycocalyx (arrows with dashed lines). (C) Surface view of $36 \mathrm{~h}$ matured biofilm with densely integrated and glycocalyx-surrounded bacteria (dashed framing) and human cells (white circle; erythrocyte).

of antiseptics and antimicrobials under challenging conditions (Rembe et al., 2018; Radischat et al., 2020).

This is especially true for newly introduced commercial agents, to provide comprehensive data on efficacy profiles in complex test scenarios and better estimate performance in in-vivo and in clinical situations. The presented work aimed 

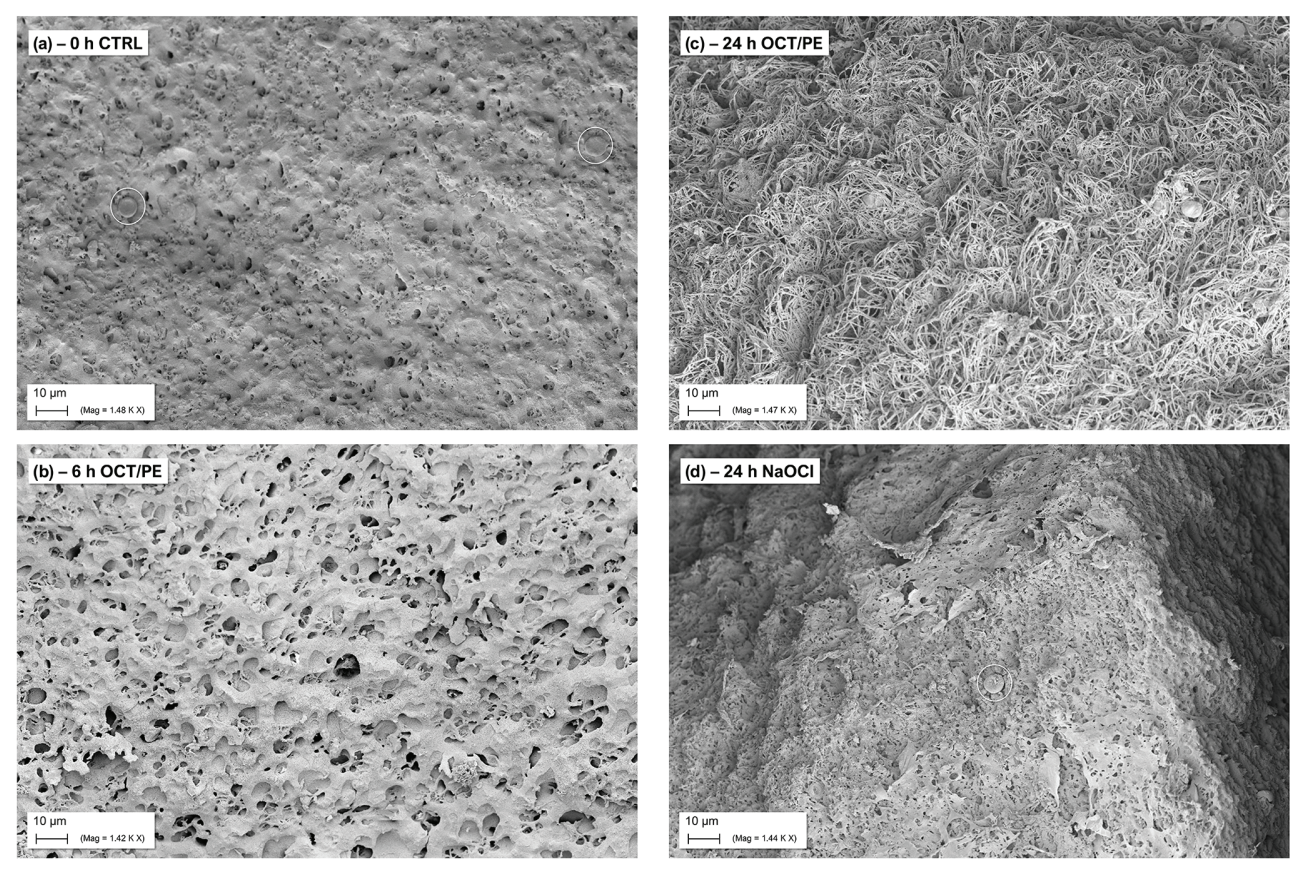

FIGURE 5 | SEM visualization of biofilm surface alteration in the hpBIOM (here P. aeruginosa) under treatment with antiseptics and antimicrobial wound irrigation solutions. (A) Densely connected surface structure of a 12 h-maturated biofilm before treatment, white circles depict human erythrocytes. (B) After 6 h of treatment with OCT/PE: surface structure appears less compact with several holes as potential entry points. (C) After $24 \mathrm{~h}$ of treatment with OCT/PE: surface is deranged and "broken-open" into a loosened structure with fine filaments, readily penetrable. (D) After $24 \mathrm{~h}$ of treatment with <0.08\% NaClO: remaining densely connected surface structure, no visible penetration, additional build-up superficial EPS structures (white circle depicts human erythrocyte).

to provide such data for commercially available chlorine-based agents $(\mathrm{HOCl}, \mathrm{NaOCl})$ and included the current "best-practice" antiseptic/antimicrobial agents as base of reference (OCT/PE and PHMB-based irrigation solution).

The presented results on antimicrobial hypochlorous wound irrigation solutions thereby highlight the necessity for complex evaluation models, as well as the careful distinction between agent classes. Generally, differentiation between an antiseptic agent and an antimicrobial wound irrigation solution is important: an antiseptic agent is a highly effective, chemical agent designated to eliminate microorganisms via a direct, pharmacological mode of action. An antimicrobial irrigation solution, on the other hand, has a primarily mechanistic approach, reducing microorganisms by means of dilution, mechanical detachment via washing off microorganisms from surfaces such as wounds and additional effects, such as lowering surface tension, $\mathrm{pH}$ modulation, preservation, and antimicrobial efficacy depending on nature and concentration of added active ingredient. Differentiation between these kinds of solutions is key for therapeutic implications, indications, and correct application in clinical practice. Otherwise, misguided expectations of, for example, a sufficient antibacterial or anti-biofilm effect, lead to insufficient local treatment. While antiseptics mostly undergo a more rigorous evaluation process regarding antimicrobial efficacy before commercial introduction, irrigation solutions are often licensed as medical devices with certain additives but a primary mechanistical mode of action. That makes licensing legitimately easier, however, classification in the field of anti-infective (antimicrobial, antiseptic, and anti-biofilm) agents reasonably more complicated since comprehensive efficacy evaluations are not provided. Oftentimes, antimicrobial modes of action are transferred from general concepts and similar agents or products without actually providing data, or only very basic, on the product itself in its specific formulation (considering concentration, $\mathrm{pH}$, volume, etc.). In case of hypochlorous wound irrigation solutions, the generalized transferred concept is the "oxidative burst," a defensive mechanism used by the human innate immune system, specifically neutrophils, via the conversion of $\mathrm{H}_{2} \mathrm{O}_{2}$ to $\mathrm{HClO}$, a bactericidal agent, using the enzyme myeloperoxidase (Wang et al., 2007). While this effect might be highly efficient in endogenous pathogen defense, differences such as local concentrations, duration of exposure, endogenous production as needed, and other factors need to be accounted for if comparing endogenously produced $\mathrm{HClO}$ and externally administered $\mathrm{HClO}$ formulations. Such extrapolations often result in insufficient differentiation of antiseptics and antimicrobial irrigation solutions in wound care regarding their efficacy, with the potential risk of insufficient local anti-infective and anti-biofilm treatment. For these reasons, clearly and specific evaluated antimicrobial and anti-biofilm efficacy profiles for antiseptics as well as antimicrobial irrigation solutions in test setups "as-close-as-possible" to real life scenarios are necessary.

In a previous publication (Severing et al., 2019), we demonstrated and discussed the differences between commercially available hypochlorous wound irrigation solutions depending on agent 
concentration, $\mathrm{pH}$-value, and test setup against planktonic bacteria, whereby LVX, KSL, and especially AMF showed a high shortterm efficacy on planktonic bacteria. The results of the now presented work are based on these preliminary evaluations and extend them in terms of potential anti-biofilm efficacy. Unfortunately, no efficacy of either agent could be detected in the human biofilm model (hpBIOM) over the course of $72 \mathrm{~h}$ (Figure 1). The antiseptic reference agent OCT/PE and the PHMB-based irrigation solution, on the contrary, achieved significantly higher reductions of microorganisms (Figures $\mathbf{2 A}-\mathbf{C}$ ) and visual breaking open of biofilm structures (Figures $\mathbf{5 A}-\mathbf{C}$ ). In contrast to our earlier publication (Severing et al., 2019), hypochlorous agents not only failed to reduce microbial counts in a biofilm setup but also in the planktonic method (QSM; Figure 1). This is however most likely attributed to the experimental setup with a deliberately chosen lower "agent to microbial test suspension"-ratio in the planktonic QSM (1:5 compared to 8:1 in standards), to unify the ratio in both models (QSM and hPBIOM). OCT/PE and PHMB, however, still achieved complete eradication of all tested planktonic microorganisms within $6 \mathrm{~h}$ in the QSM (Figures 2A-C) even in low ratio setups. In a planktonic setup with higher volumes of hypochlorous irrigation solutions, higher reduction rates were achieved (Severing et al., 2019). These results standing in contrast to earlier studies on the efficacy of chlorine-based and comparable agents, at the same time underline the necessity for careful distinction of agent and solution formulations, as well as test settings. The discrepancies in studies evaluating different forms of chlorine-based solutions, reporting higher efficacies than reported here, mainly derive from the vast heterogeneity of study designs. Many in-vitro studies used stationary biofilms on plastic surfaces without organic challenge (D'Atanasio et al., 2015; Day et al., 2017; Romanowski et al., 2018), even though the relevance of such challenge has been widely acknowledged (Brackman and Coenye, 2016; Sato et al., 2019). Especially the influence of high and differential protein loads have been described as a major influential factor of antimicrobial efficacy (Kapalschinski et al., 2017; Radischat et al., 2020) and a study by Johani et al. (2018) directly demonstrates the loss of efficacy of relevant antimicrobial substances in short term application on in-vitro vs. in-vivo models, also for hypochlorous agents.

Also, as outlined earlier, the exact composition of solutions needs to be considered, differentiating between solutions containing mainly sodium-hypochlorite, hypochlorous acid, or both, as well as the concentration and $\mathrm{pH}$ of solution. Our previous publication demonstrates the increased efficacy of higher vs. lower concentrated chlorine-based solutions (Severing et al., 2019) on planktonic bacteria. The same pattern can be observed against biofilms in the here presented results, where the higher concentrated AMF $(0.2 \% \mathrm{NaClO})$ is the only tested chlorine-based agent exhibiting any anti-biofilm effect (Figure 3B). However, this effect only occurs under increased volume and extended exposure. Compared to the antiseptic OCT/PE or the PHMB solution, the effect is still negligible and even though significantly increased compared to lower volumes, probably irrelevant in clinical practice. An additional influential aspect to be considered is the $\mathrm{pH}$ of evaluated solutions: more extreme acidic or alkaline preparations prove more effective (Percival et al., 2014; D’Atanasio et al., 2015; Wiegand et al., 2015; Day et al., 2017; Severing et al., 2019). Agents with acidic $\mathrm{pH}$ values in the work of D'Atanasio et al. (acidic solution with $\mathrm{pH}<3$ ) or Day et al. (acidic solution with $\mathrm{pH}$ of 5.5) or alkaline $\mathrm{pH}$ values (AMF with $\mathrm{pH}$ of 9.5), achieved effective microbial reductions compared to rather neutral $\mathrm{pH}$ ranges ( $\mathrm{pH}$ of 6.5-8.7; e.g., LVX and KSL).

Further relevant aspects influencing the efficacy of especially antimicrobial wound irrigation solutions are substance volume and mechanical detachment under actual irrigation. To investigate whether an increase in substance volume would yield an improved anti-biofilm effect of hypochlorous solutions, the volume capabilities of the hPBIOM were exhausted to administer as much agent as possible (increasing the volume $>3$-fold to $1.0 \mathrm{ml}$ ). The reference substances OCT/PE and PHMB exhibited a significant increase in anti-biofilm efficacy, with OCT/PE and $\mathrm{PHMB}$ achieving complete eradication of $P$. aeruginosa (Figure 3A) and OCT/PE also eradicating MRSA biofilms within $72 \mathrm{~h}$. The only hypochlorous solution, demonstrating an increase in efficacy compared to the lower volume was AMF (Figures 3A,B) with LVX and KSL showing no effect (Supplementary Table 2). Also, in case of AMF, the increased effect compared to the lower volume is rather irrelevant with at best $1.35 \pm 0.58 \log _{10}$ reduction compared to initial bacterial counts within $72 \mathrm{~h}$ (Figure 3B). For the reference substances on the contrary, the increase in administered volume as well as a prolonged exposure not only demonstrates a statistical significance regarding efficacy improvement but also proves clinically relevant by achieving the high reduction of bacterial counts $\left(\geq 3 \log _{10}\right.$ reduction steps; Figures 3 A,B) generally demanded from antiseptics under challenging conditions (DIN, 2013). This underlines the dose-dependency and differential approach antiseptics and antimicrobial irrigation solutions apply ("pharmacological" vs. "mechanical") in terms of antimicrobial efficacy. The relevance of additional aspects such as dilution, mechanical detachment/debridement, and reduction in surface tension to the overall antimicrobial and cleansing effects of especially wound irrigation solutions reported in other studies (Kammerlander et al., 2011; Assadian et al., 2018) is indirectly highlighted here. On the other hand, this aspect needs to be accounted for as a limitation to this study and the here reported results: the intention of this work was to evaluate the anti-biofilm effect of the antimicrobial hypochlorous agents within antimicrobial wound irrigation solutions compared to a PHMB-based irrigation solution and the antiseptic OCT/PE. Additionally, the approach of simple increase in volume and duration of application to ameliorate antimicrobial efficacy of hypochlorous agents was to be evaluated, however, demonstrated no relevant improve in performance in contrast to PHMBbased solutions or OCT/PE (Figures 3A,B). Nevertheless, in clinical usage, the mechanical detachment effect and repetitive application, that cannot be adequately reproduced in the experimental approach used here, may result in an increased reduction of microbial and even biofilm burden. Naturally, concentration as well as applied volume cannot be infinitely increased due to potential limiting side-effects and toxicity, which needs to be acknowledged in the evaluation of antimicrobial 
and antiseptic agents. Thereby, especially highly potent agents exert a higher cytotoxicity potential, whereby antimicrobial efficacy and cytotoxicity rise directly proportional to each other as demonstrated in several earlier studies (Hirsch et al., 2010; Severing et al., 2019). Herein lies another potential benefit of irrigation solutions with antimicrobial additives such as hypochlorous agents: while the sole antimicrobial efficacy is relevantly less compared to other agents, the likewise relevantly lower cytotoxicity allows for a far higher safely administrable substance volume, potentially making up for the lower direct antimicrobial effect via dilution an mechanical cleansing. This is most certainly the case for the decontamination and decolonization of chronic wounds, where the regenerating wound bed is to be protected from negative toxic influence and only a somewhat lower antimicrobial effect is desired.

The reported results highlight the necessity to apply antimicrobial irrigation solutions and antiseptics for a sufficient amount of time, to achieve biofilm penetration and effectively reduce bacterial counts (if used alone). The difficulty of biofilm penetration observed here indirectly confirms the current "state of the art" treatment approach of combining local antimicrobial treatment with debridement to mechanically break open dense biofilm structures and facilitate antimicrobial penetration. Generally, data on agent specific efficacy profiles need to be extended and investigated in more comprehensive and complex models to avoid confusion and misconception. Agent classification and situation-based therapeutic regimens are needed with distinguishing between highly potent antiseptics, more and less effective antimicrobial irrigation solutions and neutral irrigation solution in modern complex wound management.

Low-dosed, (near-)neutral pH hypochlorous wound irrigation solutions seem unsuitable for sole and first-line anti-biofilm treatment based on the inability to reduce bacterial counts in this complex hpBIOM. Naturally, these results should be translated to clinical practice with caution since above discussed limitations as well as further aspects such as the use of mono-species biofilms, short maturation times $(12 \mathrm{~h})$, and the unclear effect of repetitive extensive volume irrigation, still apply. However, more mature and multi-species biofilms would exhibit even higher bacterial resilience, as partly already demonstrated in another work of our research group (Besser et al., 2020) and, therefore, pose an even greater challenge for hypochlorous irrigation solutions. The antibiofilm capacities in terms of eradication and antimicrobial effect of such wound irrigation solutions are, therefore, limited. The potential dilution and mechanical detachment of early,

\section{REFERENCES}

Assadian, O., Kammerlander, G., Geyrhofer, C., Luch, G., Doppler, S., Tuchmann, F., et al. (2018). Use of wet-to-moist cleansing with different irrigation solutions to reduce bacterial bioburden in chronic wounds. J. Wound Care 27 (Suppl. 10), S10-S16. doi: 10.12968/jowc.2018.27.Sup10.S10

Besser, M., Dietrich, M., Weber, L., Rembe, J. D., and Stuermer, E. K. (2020). Efficacy of antiseptics in a novel 3-dimensional human plasma biofilm model (hpBIOM). Sci. Rep. 10:4792. doi: 10.1038/s41598-020-61728-2 loosely attached microorganisms combined with the additive effect of a low-ranging antimicrobial efficacy, rather support hypochlorous wound irrigation solutions as suited for decontamination and decolonisation of acute and chronic wounds and, therefore, prevention of (re-)contamination/ infection, rather than primary treatment of mature biofilms.

\section{DATA AVAILABILITY STATEMENT}

The datasets used and/or analyzed during the current study are available from the corresponding author on reasonable request or are available as supplementary data files.

\section{AUTHOR CONTRIBUTIONS}

JDR, LH, and ES designed the study. JDR and LH performed experiments, data analysis, and drafted the figures. $\mathrm{MB}$ and IP helped with data analysis, interpretation, and experimental setup. IP and LH performed SEM imaging. JDR, LH, and ES drafted and finalized the manuscript. All authors contributed to the article and approved the submitted version.

\section{FUNDING}

The work was supported by the internal grant program of the Faculty of Health at Witten/Herdecke University, Germany (IFF2018-61) and the German "Initiative Chronische Wunde e.V." (ICW e.V.).

\section{ACKNOWLEDGMENTS}

The authors would like to thank Martin Arnold, Susanne Haußmann, and Ella Naumova for their assistance in conducting the scanning electron microscopy.

This manuscript has been released as a pre-print at Research Square (Rembe et al., 2020).

\section{SUPPLEMENTARY MATERIAL}

The Supplementary Material for this article can be found online at: https://www.frontiersin.org/articles/10.3389/fmicb.2020.564513/ full\#supplementary-material

Besser, M., Terberger, J., Weber, L., Ghebremedhin, B., Naumova, E. A., Arnold, W. H., et al. (2019). Impact of probiotics on pathogen survival in an innovative human plasma biofilm model (hpBIOM). J. Transl. Med. 17:243. doi: 10.1186/s12967-019-1990-4

Brackman, G., and Coenye, T. (2016). In vitro and in vivo biofilm wound models and their application. Adv.Exp. Med.Biol. 897, 15-32.doi: 10.1007/5584_2015_5002

D’Atanasio, N., Capezzone de Joannon, A., Mangano, G., Meloni, M., Giarratana, N., Milanese, C., et al. (2015). A new acid-oxidizing solution: assessment of its role on methicillin-resistant Staphylococcus aureus (MRSA) biofilm morphological changes. Wounds 27, 265-273. 
Day, A., Alkhalil, A., Carney, B. C., Hoffman, H. N., Moffatt, L. T., and Shupp, J. W. (2017). Disruption of biofilms and neutralization of bacteria using hypochlorous acid solution: an in vivo and in vitro evaluation. Adv. Skin Wound Care 30, 543-551. doi: 10.1097/01.ASW.0000526607.80113.66

DIN (2013). EN 13727:2012+A1:2013. Chemical disinfectants and antisepticsQuantitative suspension test for the evaluation of bactericidal activity in the medical area-Test method and requirements (phase 2, step 1); German version.

Hall-Stoodley, L., and Stoodley, P. (2009). Evolving concepts in biofilm infections. Cell. Microbiol. 11, 1034-1043. doi: 10.1111/j.1462-5822.2009.01323.x

Hirsch, T., Koerber, A., Jacobsen, F., Dissemond, J., Steinau, H. U., Gatermann, S., et al. (2010). Evaluation of toxic side effects of clinically used skin antiseptics in vitro. J. Surg. Res. 164, 344-350. doi: 10.1016/j.jss.2009.04.029

Hoiby, N., Bjarnsholt, T., Givskov, M., Molin, S., and Ciofu, O. (2010). Antibiotic resistance of bacterial biofilms. Int. J. Antimicrob. Agents 35, 322-332. doi: 10.1016/j.ijantimicag.2009.12.011

Hoiby, N., Bjarnsholt, T., Moser, C., Bassi, G. L., Coenye, T., Donelli, G., et al. (2015). ESCMID guideline for the diagnosis and treatment of biofilm infections 2014. Clin. Microbiol. Infect. 21 (Suppl. 1), S1-S25. doi: 10.1016/j.cmi.2014.10.024 IWII (2016). Wound infection in clinical practice. Wounds International.

James, G. A., Swogger, E., Wolcott, R., Pulcini, E., Secor, P., Sestrich, J., et al. (2008). Biofilms in chronic wounds. Wound Repair Regen. 16, 37-44. doi: 10.1111/j.1524-475X.2007.00321.X

Johani, K., Malone, M., Jensen, S. O., Dickson, H. G., Gosbell, I. B., Hu, H., et al. (2018). Evaluation of short exposure times of antimicrobial wound solutions against microbial biofilms: from in vitro to in vivo. J. Antimicrob. Chemother. 73, 494-502. doi: 10.1093/jac/dkx391

Kammerlander, G., Assadian, O., Eberlein, T., Zweitmuller, P., Luchsinger, S., and Andriessen, A. (2011). A clinical evaluation of the efficacy and safety of singlet oxygen in cleansing and disinfecting stagnating wounds. J. Wound Care 20, 149-158. doi: 10.12968/jowc.2011.20.4.149

Kapalschinski, N., Seipp, H. M., Kuckelhaus, M., Harati, K. K., Kolbenschlag, J. J., Daigeler, A., et al. (2017). Albumin reduces the antibacterial efficacy of wound antiseptics against Staphylococcus aureus. J. Wound Care 26, 184-187. doi: 10.12968/jowc.2017.26.4.184

Koo, H., Allan, R. N., Howlin, R. P., Stoodley, P., and Hall-Stoodley, L. (2017). Targeting microbial biofilms: current and prospective therapeutic strategies. Nat. Rev. Microbiol. 15, 740-755. doi: 10.1038/nrmicro.2017.99

Malone, M., Bjarnsholt, T., McBain, A. J., James, G. A., Stoodley, P., Leaper, D., et al. (2017). The prevalence of biofilms in chronic wounds: a systematic review and meta-analysis of published data. J. Wound Care 26, 20-25. doi: 10.12968/jowc.2017.26.1.20

Maurer, H. R. (2001). Bromelain: biochemistry, pharmacology and medical use. Cell. Mol. Life Sci. 58, 1234-1245. doi: 10.1007/PL00000936

Pavan, R., Jain, S., Shraddha, , and Kumar, A. (2012). Properties and therapeutic application of bromelain: a review. Biotechnol. Res. Int. 2012:976203. doi: $10.1155 / 2012 / 976203$

Percival, S. L. (2017). Importance of biofilm formation in surgical infection. Br. J. Surg. 104, e85-e94. doi: 10.1002/bjs.10433

Percival, S. L., McCarty, S., Hunt, J. A., and Woods, E. J. (2014). The effects of $\mathrm{pH}$ on wound healing, biofilms, and antimicrobial efficacy. Wound Repair Regen. 22, 174-186. doi: 10.1111/wrr.12125

Percival, S. L., McCarty, S. M., and Lipsky, B. (2015). Biofilms and wounds: an overview of the evidence. Adv. Wound Care 4, 373-381. doi: 10.1089/ wound.2014.0557

Percival, S. L., and Suleman, L. (2015). Slough and biofilm: removal of barriers to wound healing by desloughing. J. Wound Care 24, 498-510. doi: 10.12968/ jowc.2015.24.11.498

Radischat, N., Augustin, M., Herberger, K., Wille, A., and Goroncy-Bermes, P. (2020). Influence of human wound exudate on the bactericidal efficacy of antiseptic agents in quantitative suspension tests on the basis of European Standards (DIN EN 13727). Int. Wound J. 17, 781-789. doi: 10.1111/ iwj. 13336

Rembe, J. D., Fromm-Dornieden, C., Bohm, J., and Stuermer, E. K. (2018). Influence of human acute wound fluid on the antibacterial efficacy of different antiseptic polyurethane foam dressings: an in vitro analysis. Wound Repair Regen. 26, 27-35. doi: 10.1111/wrr.12612

Rembe, J. D., Huelsboemer, L. F., Besser, M., and Stuermer, E. K. (2020). Anti-biofilm activity of antimicrobial hypochlorous wound irrigation solutions compared to common wound antiseptics and bacterial resilience in an innovative in-vitro human plasma biofilm model (hpBIOM). Research Square [Preprint]. doi: 10.21203/rs.3.rs-22421/v1

Romanowski, E. G., Stella, N. A., Yates, K. A., Brothers, K. M., Kowalski, R. P., and Shanks, R. M. Q. (2018). In vitro evaluation of a hypochlorous acid hygiene solution on established biofilms. Eye Contact Lens 44 (Suppl. 2), S187-S191. doi: 10.1097/ICL.0000000000000456

Salisbury, A. M., Woo, K., Sarkar, S., Schultz, G., Malone, M., Mayer, D. O., et al. (2018). Tolerance of biofilms to antimicrobials and significance to antibiotic resistance in wounds. Surg. Technol. Int. 33, 59-66.

Sato, A., Yamaguchi, T., Hamada, M., Ono, D., Sonoda, S., Oshiro, T., et al. (2019). Morphological and biological characteristics of Staphylococcus aureus biofilm formed in the presence of plasma. Microb. Drug Resist. 25, 668-676. doi: $10.1089 / \mathrm{mdr} .2019 .0068$

Schultz, G., Bjarnsholt, T., James, G. A., Leaper, D. J., McBain, A. J., Malone, M., et al. (2017). Consensus guidelines for the identification and treatment of biofilms in chronic nonhealing wounds. Wound Repair Regen. 25, 744-757. doi: $10.1111 /$ wrr. 12590

Schwartz, J. A., Goss, S. G., Facchin, F., Avdagic, E., and Lantis, J. C. (2014). Surgical debridement alone does not adequately reduce planktonic bioburden in chronic lower extremity wounds. J. Wound Care 23, S4-S13. doi: 10.12968/ jowc.2014.23.Sup9.S4

Schwarzer, S., James, G. A., Goeres, D., Bjarnsholt, T., Vickery, K., Percival, S. L., et al. (2019). The efficacy of topical agents used in wounds for managing chronic biofilm infections: a systematic review. J. Infect. 80, 261-270. doi: 10.1016/j.jinf.2019.12.017

Severing, A. L., Rembe, J. D., Koester, V., and Stuermer, E. K. (2019). Safety and efficacy profiles of different commercial sodium hypochlorite/hypochlorous acid solutions ( $\mathrm{NaClO} / \mathrm{HClO})$ : antimicrobial efficacy, cytotoxic impact and physicochemical parameters in vitro. J. Antimicrob. Chemother. 74, 365-372. doi: $10.1093 / \mathrm{jac} / \mathrm{dky} 432$

Shukla, S. K., Sharma, A. K., Gupta, V., Kalonia, A., and Shaw, P. (2020). Challenges with wound infection models in drug development. Curr. Drug Targets. doi: 10.2174/1389450121666200302093312 [Epub ahead of print]

Stoffel, J. J., Kohler Riedi, P., and Hadj Romdhane, B. (2020). A multi-model regime for evaluating effectiveness of antimicrobial wound care products in microbial biofilms. Wound Repair Regen. 28, 438-447. doi: 10.1111/ wrr. 12806

Wang, L., Bassiri, M., Najafi, R., Najafi, K., Yang, J., Khosrovi, B., et al. (2007). Hypochlorous acid as a potential wound care agent: part I. stabilized hypochlorous acid: a component of the inorganic armamentarium of innate immunity. J. Burns Wounds 6:e5.

Wiegand, C., Abel, M., Ruth, P., Elsner, P., and Hipler, U. C. (2015). pH influence on antibacterial efficacy of common antiseptic substances. Skin Pharmacol. Physiol. 28, 147-158. doi: 10.1159/000367632

Wolcott, R. D., Rumbaugh, K. P., James, G., Schultz, G., Phillips, P., Yang, Q., et al. (2010). Biofilm maturity studies indicate sharp debridement opens a time-dependent therapeutic window. J. Wound Care 19, 320-328. doi: 10.12968/ jowc.2010.19.8.77709

Conflict of Interest: The authors declare that the research was conducted in the absence of any commercial or financial relationships that could be construed as a potential conflict of interest.

Copyright (C) 2020 Rembe, Huelsboemer, Plattfaut, Besser and Stuermer. This is an open-access article distributed under the terms of the Creative Commons Attribution License (CC BY). The use, distribution or reproduction in other forums is permitted, provided the original author(s) and the copyright owner(s) are credited and that the original publication in this journal is cited, in accordance with accepted academic practice. No use, distribution or reproduction is permitted which does not comply with these terms. 


\section{GLOSSARY}

\begin{tabular}{|c|c|}
\hline Term & Definition \\
\hline AMF & Actimaris ${ }^{\circledR}$ forte \\
\hline $\mathrm{CaCl}_{2}$ & Calcium chloride \\
\hline $\mathrm{CFU}$ & Colony forming units \\
\hline CSA & Casein/soy peptone agar \\
\hline CTRL & Control \\
\hline DIN & German institute for standardization \\
\hline DRK & German red cross \\
\hline $\mathrm{DSMZ}$ & German Collection of Microorganisms and Cell Cultures \\
\hline $\mathrm{ddH}_{2} \mathrm{O}$ & Double distilled water \\
\hline $\mathrm{ECM}$ & Extracellular matrix \\
\hline EPS & Extracellular polymeric substance \\
\hline $\mathrm{HCL}$ & Hydrochloride \\
\hline $\mathrm{HClO}$ & Hypochlorous acid \\
\hline hpBIOM & Human plasma biofilm model \\
\hline KSL & Kerrasol $^{\circledR}$ \\
\hline LVX & Lavanox $^{\circledast}$ \\
\hline MRSA & Methicillin-resistent S. aureus \\
\hline MSSA & Methicillin-susceptible S. aureus \\
\hline $\mathrm{NaClO}$ & Sodium hypochlorite \\
\hline $\mathrm{NaNO}_{2}$ & Sodium nitrite \\
\hline OCT/PE & Octenidine dihydrochloride/phenoxyethanol \\
\hline $\mathrm{OsO}_{4}$ & Osmium tetroxide \\
\hline PBS & Phosphate buffered saline \\
\hline PHMB & Polyhexamethylene-biguanide \\
\hline PVP & Polyvinylpyrrolidone \\
\hline QSM & Quantitative suspension method \\
\hline RT & Room temperature \\
\hline SEM & Scanning electron microscopy \\
\hline sem & Standard error of the mean \\
\hline SDS & Sodium dodecyl sulfate \\
\hline
\end{tabular}

